\title{
HIGH-PERFORMANCE COMPUTER APPLICATIONS IN THE BEHAVIORAL SCIENCES
}

\section{Editorial}

This issue of Behavior Research Methods, Instruments, \& Computers is devoted to the Symposium on High-Performance Computer Applications in the Behavioral Sciences, held in Minneapolis, Minnesota, May 10-12, 1996. The symposium was organized by Lynne K. Edwards, University of Minnesota, who served as editor for this special issue of BRMIC. Co-organizers were Stephen W. Link, of the Federation of Behavioral, Psychological and Cognitive Sciences, and Cynthia H. Null, of NASA Ames Research Center, both of whom served as associate editors for this issue. The conference was sponsored and financed by the University of Minnesota Supercomputer Institute and supported by the Federation of Behavioral, Psychological and Cognitive Sciences. The University of Minnesota College of Education and Human Development provided ten additional scholarships for local attendees.

The purpose of the conference was to advance the state of the art in scientific computation with respect to the behavioral sciences. The symposium opened with a paper, "Scientific Computation: An Interdisciplinary Approach at Minnesota." Eleven invited papers were presented, two in each of five sessions-High-Performance Computing and Psychological Models, High-Performance Computing and Human Vision I and II, High-Performance Computing and Neural and Physiological Processes, and High-Performance Computing and Statistical Analysis - and one in a final overview session, High-Performance Computing and Its Promises for the Behavioral Sciences. Each session included in addition a commentary on the papers given in that session. Three technical papers from vendors were also presented.

The application of high-performance computers to the behavioral sciences is in its infancy. The papers from this symposium represent cutting edge work in the area and illustrate the unlimited potential for behavioral research afforded by high-performance computation.

Robert W. Proctor Editor 